Measuring the feeling of distant intimacy with politicians across countries: Development, construct validity, and replicability of the parasocial relationship with a political figure (PSR-P) scale

\author{
Moh Abdul Hakim ${ }^{1,2}$ \\ James H. Liu ${ }^{1}$ \\ Massey University, New Zealand ${ }^{1}$ \\ Universitas Sebelas Maret, Indonesia ${ }^{2}$
}

Running head: PARASOCIAL RELATIONSHIP WITH POLITICAL FIGURES

Word count: 9,193

Address correspondence to:

Moh Abdul Hakim

School of Psychology

Massey University

Private Bag 102-904

North Shore

Auckland 0745

Email: m.a.hakim@staff.uns.ac.id

The first author acknowledged the supports from the Doctoral Scholarship Program of Lembaga Pengelola Dana Pendidikan (The Indonesian Endowment Fund for Education). All data and code used in the present study are available at Harvard Dataverse: https://doi.org/10.7910/DVN/F3KS7M. 
PARASOCIAL RELATIONSHIPS WITH POLITICIANS

\begin{abstract}
Parasocial theory views ordinary people's emotional bonding with political figures as a form of parasocial relationship. As existing measures of parasocial relationship have been criticised conceptually and psychometrically, we developed a new scale of parasocial relationship with a political figure (PSR-P). Construct validity, factor replicability and measurement invariance were assessed, based on samples from diverse countries (Indonesia, New Zealand, and the USA) with different political systems. In three studies using a panel of experts ( $\mathrm{N}=20$; Study 1), a convenience sample of adults $(\mathrm{N}=212$; Study 2$)$, and representative and cross-country samples ( $N=897$; Study 3), we found that the four-item PSR-R scale provided satisfactory construct validity (i.e. convergent, discriminant, and predictive validity), replicable factor structure with measurement invariance, and predictable results based on socio-political context. The PSR-P scale can be used to advance measurement and applications of parasocial theory in the field of social and political psychology.
\end{abstract}

Keywords: parasocial theory, parasocial relationships, political figures, measurement invariance, construct validation 
PARASOCIAL RELATIONSHIPS WITH POLITICIANS

\section{Measuring the feeling of distant intimacy with politicians across countries: \\ Development, construct validity, and replicability of the parasocial relationship with a political figure (PSR-P) scale}

\section{Introduction}

Individuals' personal bonding with political figures is regarded as an important feature of political behaviour in contemporary democracies (Garzia, 2011, 2013; Lobo \& Curtice, 2014; Schneider, 1994). Many political leaders around the world, from Donald Trump in the United States, to Joko Widodo in Indonesia, and Jacinda Ardern in New Zealand, are known to have the ability to mobilise support from a large portion of voters who are attached to them emotionally and personally. Theoretically, such political attachment is unique for several reasons. First, it tends to be little influenced by political ideology, but instead revolves around emotions (Lenz, 2013; Schneider, 1994). Second, bonding with political figures departs from traditional institution-based political attachments, such as party identity or partisanship (Lobo \& Curtice, 2014). Third, some scholars observe that the sense of personal bonding with figures entails certain motivational components which may drive ordinary citizens to engage more politically (Dunn \& Nisbett, 2014; Gabriel, Paravati, Green, \& Flomsbee, 2018).

Existing literatures within the fields of social and political psychology have mostly explained such political dispositions in terms of authoritarian personality or authoritarianism (Adorno, Frenkel-Brunswik, Levinson, \& Sanford, 1950; Duckitt, 2001), partisanship, political ideology, issue proximity, and congruence of traits and values to the candidates (Caprara \& Zimbardo, 2004; Garzia, 2013; Weisberg \& Rusk, 1970). Parasocial theory offers an alternative approach in which such political bonding may be viewed as a form of parasocial relationship 
(PSRs) - that is, an enduring, long-term, and usually positive, one-sided form of relational "intimacy" that may develop toward public figures such as celebrities, sportsmen, and politicians (Horton \& Wohl, 1956; Klimmt, Hartmann, \& Schramm, 2006; Stever, 2017). The construct of parasocial relationships with political figures, as J. Cohen and Holbert (2018) asserted, may extend current models of political behaviour by more emphasising its interpersonal rather than ideological or group-based elements.

Despite the important insights promised by parasocial theory, there are critical aspects of its measurement that might hinder the application of the theory in the field of social and political psychology. First of all, existing measures of its key psychological constructs have been criticized conceptually and psychometrically. Since the publication of seminal work by Rubin et al. (A. M. Rubin \& Perse, 1987; A. M. Rubin, Perse, \& Powell, 1985) the Parasocial Interaction (PSI) scale has become the most frequently used scale to assess various forms of parasocial relationships, and also has been adopted into political contexts (J. Cohen \& Holbert, 2018). However, recent critical reviews of the theory have concerned limitations of the scale and its derivatives. Dibble et al. (2016), for instance, assert that the PSI scale has not been adequately put through construct validation tests, especially using external criteria. Moreover, the scale may have overlooked critical distinctions between two parasocial concepts: parasocial interaction and parasocial relationships (Schramm \& Wirth, 2010; these conceptual issues to be discussed). Scales that are designed to specifically measures parasocial relationships are, therefore, needed.

Furthermore, virtually all published parasocial relationships (PSRs) and parasocial interaction (PSI) scales are developed within the context of mass media and popular culture studies, designed to capture parasocial bonding with various media figures or personae such as 
celebrities, sportsmen, and broadcasters. Given that the domain of politics is somewhat different from the contextual origin of these scales, some of the indicators seem to be qualitatively less relevant to assess people's experiences of being in parasocial relationships with politicians. For instance, Tuchakinsky‘s (2010) parasocial relationship scale put some emphasis on romantic and sexual experiences related to the admired celebrities which may not be applicable to politicians in general (also see Slater, Ewoldsen, \& Woods, 2018). This limits the content validity of these scales, which as Hinkin (1998) asserts, is one of the critical elements of a psychometrically sound scale.

In addition, existing scales of political parasocial relationships have used 12 and 13 indicators which may not be efficient to measure a single factor (see Dunn \& Nisbett, 2014; J. Cohen \& Holbert, 2018). On the other hand, psychologists are increasingly interested in brief yet powerful scales to avoid the likeliness of fatigue, boredom and burden for survey participants (Milojev, Osborne, Greaves, Barlow, \& Sibley, 2013; Romero,Villar, Gómez-Fraguela, \& LópezRomero, 2012), which may increase response bias (Hinkin, 1998; Brown, 2014). Scale brevity, as Romero, et al (2012) pointed out, is a priority in many research situations especially in screening studies, large-scale surveys, and repeated measures experiments. The need for brief scales is particularly evident in public opinion surveys in which the questionnaire typically comprises a large set of measures targeting respondents from a general population.

Importantly, political parasocial relationships are also sensitive to the macro political contexts of a country, particularly the type of political system adopted and its degree of democratic maturity. The existing literature suggests that citizens in a presidential system are more susceptible to forming emotional bonds with their politicians (i.e. national leaders) than their counterparts in a parliamentary system (Karvonen, 2007; Lobo \& Curtice, 2014). In presidential systems such as 
the United States and Indonesia, media coverage and voters' attention is routinely focused on Presidential candidates instead of political parties, especially during elections. Conversely, in a parliamentary system like New Zealand, only indirectly do voters influence the appointment of the prime minister, which thus strengthens the central role of political parties over individual candidates. Furthermore, the degree of democratic maturity (for example, as measured by the Democracy Index; The Economist Intelligent Unit, 2018) might also become an important contextual factor for political parasocial relationships. Unlike in an established democracy, most political parties in an emerging democracy are not well established institutionally, and extensively rely on individual politicians, especially the presidential candidates, to set policy and attract voters (for instance, see Mietzner, 2015). A good measure of political parasocial relationships should thus have the ability to assess parasocial attachments with politicians reliably across countries, and yet produce scores that reflect substantive political differences across the countries examined.

Taking into account the limitations of the existing parasocial relationship scales as discussed above, the present research aims to develop a scale of parasocial relationships with political figures (PSR-P), and test its content validity (Study 1), convergent validity (Study 2), as well as its factor replicability, discriminant validity, and predictive validity (Study 3) using samples from three different countries. The newly developed PSR-P scale is expected to advance the measurement and application of parasocial theory in the field of social and political psychology.

\section{Parasocial Theory}

Parasocial theory builds on the assumption that individuals may develop a one-sided or illusionary intimacy at distance with a public figure (or a persona) by viewing her or him through 
media over time (Horton \& Wohl, 1956; Horton \& Strauss, 1957). As Horton and Wohl (1956) put it, "They [the viewers] know such a person in somewhat the same way they know their chosen friends; through direct observation and interpretation of his appearance, his gesture and voice, his conversation and conduct in a variety of situations" (p. 216). Further, the theory posits that the social psychological processes involved in parasocial relationships mirror those in real interpersonal relationships (e.g. friendships) (Horton \& Strauss, 1957). Previous research found that people who are in a parasocial relationship regard the figure of intimacy as a source of comfort and enjoyment as well as a role model (Giles, 2002; Gleason, Theran, \& Newberg, 2017). They are also motivated to actively nurture the relationship (Horton \& Wohl, 1956; R. B. Rubin \& Mchugh, 1987), and even experience grief and loss when the figure disappears. For example, this sense of loss can occur if the figure dies or withdraws from public life. (E. L. Cohen \& Hoffner, 2016; Eyal \& Cohen, 2006). Unlike real interpersonal relationships, however, parasocial relationships with public figures like celebrities and political candidates elicit asymmetry, where the fans typically exhibit a strong admiration to the figure, but this is not reciprocated by the public figure equally (Horton \& Strauss, 1957; McCutcheon, Lange, \& Houran, 2002).

In early developments of parasocial theory, there were ambiguities concerning the conceptualization and measurement of its central concepts of parasocial relationships and parasocial interaction. In their seminal work, Horton and Wohl (1956) put forward the concept of a parasocial relationship to describe the long-term one-sided intimacy at distance that a viewer may develop towards media figures or personae. Unfortunately, this term was often used interchangeably with the notion of parasocial interaction (PSI) which refers to a simulacrum of conversational give and take with the media figure during media exposures (Horton \& Strauss, 1957; Horton \& Wohl, 1956). To solve this conceptual problem, A. M. Rubin and colleagues (A. 
M. Rubin \& Perse, 1987; R. B. Rubin \& Mchugh, 1987) proposed a broader definition of parasocial interaction as the viewers' interpersonal involvement with media or public figures, which conceptualizes parasocial interaction and relationships together as a unidimensional construct. This operational definition was used as the conceptual basis for the development of Rubin et al.'s widely adopted Parasocial Interaction (PSI) Scale (A. M. Rubin et al., 1985).

More recently, however, scholars have proposed a clear distinction between parasocial relationships and parasocial interaction (Dibble et al., 2016; Giles, 2002; Klimmt et al., 2006). They argue that, though the two constructs are closely associated, parasocial interaction and parasocial relationships differ theoretically in several meaningful ways. In terms of the nature of the constructs, it is argued that parasocial interaction stands for a media-bounded phenomenon in which the viewers experience a simulacrum of conversational give-and-take as a response to a media figure in specific media exposure situations (Giles, 2002). In contrast, a parasocial relationship refers to a one-sided and positive relationship that extends beyond the media exposure situation (Dibble et al., 2016; Schramm \& Wirth, 2010). Importantly, not all parasocial interactions with a media figure translate to parasocial relationships. Such might be the case - for example, when a given figure is disliked by the viewers (Dibble et al., 2016). Considering these distinctions, Hartmann, Schramm, and their colleagues (Klimmt et al., 2006; Schramm \& Hartmann, 2008) suggest that a parasocial relationship should be explicitly defined as the enduring and crosssituational feeling of intimacy at distance with a media or public figure. Consequently, alternative measures that are primarily designed to assess PSRs are needed (Schramm \& Wirth, 2010), especially in the context of parasocial relationships with political figures.

\section{Existing scales of political parasocial relationship}


A variety of parasocial interaction (PSI) scales (A. M. Rubin et al., 1985; A. M. Rubin \& Perse, 1987) have been modified and used in previous studies to measure parasocial relationships with political figures and their correlations with various political outcomes. Dunne and Nisbett (2014) modified 12 items from the short version of the PSI scale (A. M. Rubin \& Perse, 1987) to assess parasocial interaction with political candidates on web pages and social media. Additionally, they selected and modified five items (e.g., "the webpage shows me what this candidate is really like," "when I viewed the candidate webpage I felt like part of a group," "I see this candidate as a natural, down to earth person," "this candidate understands what I need, "and "this candidate understands what I want") to measure perceived intimacy while viewing the candidate's web page for the reason that the items describe perceptions of a reciprocal relationship

A slightly different approach was taken by Cohen and Holbert (2018), whereby they selected 12 items from the long version (20 items) of the PSI scale (A. M. Rubin et al., 1985) in devising the Political Parasocial Relationship (PPSR) scale to measure the feeling of connection to several political figures including Donald Trump, Hillary Clinton, and Paul Ryan. Interestingly, three items of this PPSR scale were almost identical to those of Dunn and Nisbett's (2014) measure of perceived intimacy with political candidates during media exposure (i.e. "when I'm watching Donald Trump, I feel as if I am part of his group," "I see Donald Trump as a natural, down-toearth person," "Donald Trump seems to understand the kinds of things I want to know"). Moreover, two items seem to be relevant to the imagery of interactions in a media exposure situation rather than being indicative of enduring feeling of intimacy (e.g. "when Donald Trump expresses how he feels about the news, it helps me make up my own mind about the media," "I like to compare my ideas with what Donald Trump says"). These seemingly diverse interpretations of the PSI items might, in fact, stem from Rubin et al.'s broad, albeit conceptually problematic 
definition of parasocial interaction which also incorporates parasocial relationships (Dibble et al., 2016; Klimmt et al., 2006).

The problem is that neither scale is devised to focus on the enduring feeling of emotional intimacy with a distant other. Given this conceptual lack, an alternative measure designed specifically to measure parasocial relationships with political figures is proposed. We developed an alternative scale of parasocial relationships with political figures (PSR-P) that explicitly measures the enduring feeling of intimacy with a political figure. This scale was devised based on Horton and Wohl's (1956) original conception of a parasocial relationship and its contemporary refinements by Hartmann and colleagues (Dibble, Hartmann, \& Rosaen, 2016; Hartmann \& Goldhoorn, 2011; Schramm \& Hartmann, 2008; Klimt, Hartmann, \& Schramm, 2006). In political contexts, the newly developed PSR-P scale may be utilised as a complement to Schramm and Hartmann's (2008) 13-item Parasocial Interaction Process Scale (PSI-Process) as modified by Gabriel et al. (2018). This scale was reported to be significantly associated with positive attitudes and trust to the figure, as well as believing in the candidate's promises and voting for him or her (Gabriel et al., 2018).

To support the utility of the new PSR-P scale, evidence of content validity (Study 1), factor structure, convergent validity, and divergent validity (Study 2), as well as factor replicability, discriminant validity, and predictive validity (Study 3) are reported, using samples from Indonesia, New Zealand, and the U.S.

\section{Study 1: Development and content validity of the PSR-P Scale}


In Study 1, we aimed to develop an item list for the PSR-P Scale and content validate these with a panel of experts. In developing the scale, we relied heavily on Horton and Wohl's (1957) and Hartmann, Schramm, \& Klimt's (2004) theoretical work to define parasocial relationships with a political figure as an enduring and cross-situational feeling of intimacy at distance that an ordinary person holds for a political figure. We used four criteria in generating the items. First, the items should tap into the socio-emotional aspects of parasocial relationships with political figures. Second, the wording of the items should be simple and straightforward so that they can be easily translated into different languages. Third, they should reflect ordinary citizens' experiences of electoral politics. Lastly, we wanted a short PSR-P Scale so that it would be practical to administer in a broad survey measuring a variety of variables, common in electoral research and polling. In so doing, we reviewed the Rubin et al.'s (Rubin et al., 1985; Rubin \& Perse, 1987) short and long version of PSI scale items including those that had been adopted for the PPSR scale. Items were translated into Bahasa Indonesian using the committee method (Brislin, 1980), and were then modified to fit our criteria. Additionally, we also conducted field observations and interviews with the supporters of Indonesian president Joko Widodo and New Zealand Prime Minister Jacinda Ardern during their election campaigns, so that we could select indicators able to gauge the precise experiences of being parasocially attached to politicians. We eventually generated seven indicators to be included in the preliminary version of a PSR-P Scale (see Table 1). Content validation was then conducted by appointing a panel of experts to judge the quality of the items. The Content Validity Ratio (CVR) for each item was calculated, as suggested by Lawshe (1975).

\section{Method}


Participants. Twenty Indonesians (9 females, 11 males; $M_{\text {Age }}=32.5$ ) were invited to be part of an expert panel to examine the content validity of the initial PSR-P Scale. The panel consisted of four social psychologists, four political psychologists, three psychometricians and two political scientists as the content experts, and seven ordinary citizens as the lay experts. Their participation was on a strictly voluntary basis, and no incentives for participation were provided.

Procedure. Experts received a link to the online validation form of the preliminary PSRP Scale. Following Lawshe's (1975) content validation method, they were first requested to review the operational definition of the construct. Then they were asked to group the seven items into one of three categories: "essential," "useful, but not essential," or "not necessary." The Content Validity Ratio (CVR) for each item was calculated to determine the level of expert agreement using the formula: $\mathrm{CVR}=(\mathrm{Ne}-\mathrm{N} / 2) /(\mathrm{N} / 2)$, where $\mathrm{Ne}$ is the number of experts rating "essential," and $\mathrm{N}$ is the total number of experts. Given that we had 20 members on the panel, 0.42 of the CVR value was set as the cut-off point following Lawshe (1975). Only items with a CVR value greater than 0.42 were included for further validation.

\section{Results}

Insert Table 1 here

The content validation of preliminary PSR-P items produced CVR values that ranged from mediocre (-0.5) to excellent (0.9). As can be seen in Table 1, Item No 7 failed to achieve the cut-off point, so it was discarded from the item list. Subsequent construct validations of the PSRP Scale were conducted based on the remaining six items. 
PARASOCIAL RELATIONSHIPS WITH POLITICIANS

\section{Study 2: Factor structure and convergent validity}

The PSR-P Scale was explicitly designed to measure a single latent factor of parasocial relationship with a political figure. To ensure that the 6 items of the PSR-P scale from Study 1

loaded onto the expected single factor, an exploratory factor analysis using Principal Axis Factoring (PAF) extraction and Varimax rotation was performed. Items that had a factor loading lower than 0.40 were excluded from the item list in order to maximise the interpretability of the latent factor (Hair, Black, Babin, Anderson, \& Tatham, 2006). A confirmatory factor analysis with MLR estimator (50,000 iterations) was used to test the factor structure of the final PSR-P Scale (Muthén \& Muthén, 2006). This included five cutoff criteria to check for the model good of fitness: non-significant chi-square $\left(\chi^{2}\right)$, RMSEA $<.06$, SRMSR $<.08$, CFI $>.95$ and TLI $>.95(\mathrm{Hu} \&$ Bentler, 1999).

Furthermore, a series of convergent validation tests were conducted using a nomological network approach (Cronbach \& Meehl, 1955), in which the PSR-P scale was expected to produce specific patterns of correlation with the PPSR and PSI-Process scales. To assess the strength of the correlations $(r)$, we used Cohen's (1988, pp. 83) criteria in which $r=.10, .30$, and .50 are considered as small, medium, and large respectively. To support the convergent validity of the scale, we expected PSR-P to show a high correlation (>.50) with PPSR, given that these scales were designed to measure the same construct (Hypothesis 1). Conversely, a medium correlation between the PSR-P and PSI-Process was expected (Hypothesis 2), considering that the latter was devised to exclusively measure parasocial interactions (Schramm \& Hartmann, 2008).

\section{Method}


Participants. Two hundred and twelve adult participants were recruited in Indonesia through online snowballing ( $62.9 \%$ female; $M_{A g e}=25.58, \mathrm{SD}_{A g e}=7.8$ ). Participants were required to be 18 years old or older, and eligible to participate in the 2019 Indonesian General Election. Their participation in this study was on a voluntary basis.

Measures and procedures. Participants who agreed with the statement of informed consent were directed to an online questionnaire consisting of the preliminary PSR-P, PPSR Scale, PSI-Process Scale, and demographic information. In administering the questionnaire, we followed the standard procedure of measuring parasocial relationships (Rubin et al., 1985), by which participants were first asked to nominate their most favoured political figure on the national stage (see Appendix for the list of political figures from Study 2). Subsequently, they were asked to respond to the item list of the preliminary PSR-P (6 items), PPSR (12 items), and PSI-Process (13 items) with reference to the nominated figure. Sample items of PPSR included: "when [the figure] expresses how he feels about the news, it helps me make up my own mind about the media", $(1=$ disagree completely to $7=$ agree completely). In addition, participants were asked to think about the figure during media exposure when responding to the PSI-Process items (Schramm \& Hartmann, 2008). Sample items of PSI-Process included "Sometimes I felt like speaking out on [the figure]", $(1=$ disagree completely to $7=$ agree completely $)$. Both PSI and PSI-Process Scale provided decent internal consistency ( 0.887 and 0.849 respectively; see Table 3 for descriptive statistics).

\section{Results}

Insert Table 2 here 
Kaiser-Meyer-Olkin (0.741) and Bartlett's sphericity tests $[\chi 2(15)=175.534, \mathrm{p}<.001]$ showed the data was adequate to perform Exploratory Factor Analysis (EFA) on the six preliminary PSR-P items (Kaiser \& Rice, 1974). We ran EFA using Principal Axis Factoring (PFA) with Varimax rotation and found that four items were highly loaded onto a conceptually coherent factor (Factor 1), while the remaining two items loaded onto a second, less interpretable factor (Item No 5 and 6; see Table 2). These two items were thus excluded from the final PSR-P scale.

Next, the retained 4 items were subjected to a confirmatory factor analysis with a MLR estimator (50,000 iterations): this showed that a single latent factor model produced satisfying fit indices, $\chi 2(2)=1.286, p=.526, \mathrm{RMSEA}=.000, \mathrm{CFI}=1, \mathrm{TLI}=1.022, \mathrm{SRMR}=.013$, and decent internal consistency, $\alpha=.707$. In contrast, we found excellent internal consistency $(\alpha=.894)$ but insufficient model fit for the PPSR scale ${ }^{1}, \chi^{2}(2)=20.39, p=.000$, RMSEA $=.208$, CFI $=.952$, $\mathrm{TLI}=.856, \mathrm{SRMR}=.032$, and good internal consistency $(\alpha=.849)$ and good model fit for the PSI-Process scale, $\chi 2(2)=1.087, p=.581, \mathrm{RMSEA}=.000, \mathrm{CFI}=1, \mathrm{TLI}=1.012, \mathrm{SRMR}=.014$ (see Table 3).

Insert Table 3 here

We then proceeded by testing the convergent validity of the final PSR-P scale using PPSR and PSI-Process as the criterion variables. As displayed in Table 3, PSR-P was highly and positively correlated with PPSR, $r=.600, p<.001$, confirming Hypothesis 1 . We also found a smaller, moderate correlation between PSR-P and PSI-Process in accord with Hypothesis 2, $r=$

\footnotetext{
${ }^{1}$ Tested based on parceled items following J. Cohen and Holbert (2018).
} 
$.451, p<.001$. Taken together, these analyses provided initial evidence for the convergent validity of the PSR-P scale.

\section{Study 3: Replicability, discriminant validity and predictive validity}

To demonstrate the replicability, validity and functionality of the PSR-P scale, the items and the factor that represents a parasocial relationship with a political figure should produce measurement invariance with samples across socio-political contexts; it should be distinguished from other relevant concepts and afford predictable relationships with criterial dependent measures (Cheung \& Rensvold, 2002). For the present study, we selected samples from three countries to test the measurement invariance of the PSR-P scale. Indonesia was chosen because it is an emerging democracy that has adopted a presidential system. The United States and New Zealand were to represent established democracies that have adopted presidential and parliamentary systems respectively (The Economist Intelligence Unit, 2018). A large body of literature suggests that a presidential system, where the political dynamics are centred around political figures rather than parties, facilitates candidate-focused political preferences more than a parliamentary system (Karvonen, 2007; Lobo \& Curtice, 2014). This might even be more prevalent in the presidential system of an emerging democracy like Indonesia, whose political parties are neither established institutionally nor based on any systematic political ideology (Mietzner, 2015).

It is expected that the PSR-P scale has the ability to equally and reliably detect parasocial relationships with political figures of citizens across political contexts (Hypothesis 3). Furthermore, it was expected that mean PSR-P scales would reflect differences in political systems and democratic maturity across Indonesia, New Zealand, and the USA (Hypothesis 4). PSR-P 
should be higher in the USA and Indonesia than New Zealand, and higher in Indonesia than the USA.

Furthermore, if the PSR-P scale is to demonstrate discriminant validity, this scale is expected to be not highly correlated with other scales designed to assess theoretically different constructs (Campbell \& Fiske, 1956). Given its unique emphasize on the sense of distant intimacy, the PSR-P scale should demonstrate that political parasocial relationship is distinguishable from other constructs that capture different psycho-political experiences. Specifically, to demonstrate its discriminant validity, a parasocial relationship with a politician should not be strongly and consistently related to other forms of political attachment based on the need for submission to a strong leader (i.e. authoritarianism; Duckitt, 2001), political ideology (Schneider, 1994), and the moral obligation to follow benevolent and morally legitimate political leaders (i.e. belief in benevolent authority; Liu, Yeh, Wu, Liu, \& Yang, 2015) across socio-political contexts

\section{(Hypothesis 5).}

Finally, just as in traditional interpersonal relationships, parasocial relationships are theorized to motivate one to nurture involvement with the figure of intimacy (Horton \& Wohl, 1956). Previous studies in the US have found that people who maintain a parasocial relationship with a political figure are more likely to have a higher interest in politics and show greater elaboration of political information, which subsequently enhances their internal efficacy in political participation (Dunn \& Nisbett, 2014). Thus, as the criteria for predictive validity, we hypothesised that PSR-P should predict political interest, political elaboration and political efficacy consistently across political contexts (Hypothesis 6).

\section{Method}


Participants. This study initially involved 1,399 adult participants ( $\geq 18$ years old) from Indonesia $(\mathrm{N}=305)$, New Zealand $(\mathrm{N}=605)$, and the U.S. $(\mathrm{N}=489)$. Participants were recruited online through a stratified quota sample recruited by Nielsen (stratified according to age, gender and region), a global media polling company on the researchers' behalf. Five hundred and two participants $(35.9 \%)$ did not mention any specific favoured political figure and were excluded from the present analysis. This exclusion was taken to ensure that the participants had a target figure in mind when responding to the PSR-P scale, thus reducing measurement error (Kerlinger, 1986; R. B. Rubin \& Mchugh, 1987). Our final samples included 897 participants, consisting of 206 Indonesians $\left(55.3 \%\right.$ female, $\left.M_{\text {Age }}=37.74, S D_{\text {Age }}=9.55\right), 366$ New Zealanders $(54.7 \%$ female, $\left.M_{\text {Age }}=53.53, S D_{\text {Age }}=15.74\right)$, and 329 Americans $\left(56 \%\right.$ female, $\left.M_{\text {Age }}=55.69, S D_{\text {Age }}=14\right)$. All participants agreed with informed consent before completing the questionnaire.

Measures. We first asked the participants to nominate their most favoured national political figure (see Appendix for the list of political figures from Study 3). The four items of the PSR-P Scale from Study 2 were then used to measure participants' sense of relationship intimacy with their favoured political figure. These items consistently showed good internal consistency across sample groups (Indonesia $=0.879 ;$ New Zealand $=0.846$; the U.S. $=0.847$; see Table 4). The questionnaire also included three variables as the criteria for discriminant validity: right-wing authoritarianism, benevolent authority, and political ideology. There were also three criterion variables for predictive validity: political interest, political elaboration, and political efficacy.

Right-wing authoritarianism (RWA). This variable was measured with a modified 4item RWA scale drawing on items developed by Duckitt (2001). The scale included items like "Obedience and respect for authority are the most important virtues children should learn", $(1=$ 
disagree completely to $7=$ agree completely). The internal consistency of this scale was decent for New Zealand (0.728) and the U.S. (0.766), but quite low for Indonesia (0.414).

Benevolent authority. This construct was measured with a four-item scale developed by Liu et al. (2015) that captured beliefs in the benevolence and moral legitimacy of leaders in central government. This scale included items such as "The leaders in our country set a good example for young people to follow" ( $1=$ disagree completely to $7=$ agree completely $)$. This scale provided good internal consistency across sample groups (Indonesia $=0.780$; New Zealand $=$ 0.849; the U.S. $=0.794)$.

Political ideology. This was measured with three items modified from the European Social Survey (ESS), tapping into one's orientations on political, economic, and social issues in term of liberal-conservative ideology. The sample items included "On political issues, where would you place yourself on a scale of $0-10$, where $10=$ Strong conservative and $0=$ Strong liberal". This scale showed very good internal consistency for each sample group (Indonesia = 0.917; New Zealand $=0.938$; the U.S. $=0.959$ ).

Political interest. This was measured with a single item derived from the World Values Survey asking, "How interested are you in information about what's going on in politics and public affairs?" $(1=$ not at all to $7=$ a great deal $)$. This scale has been well validated in almost 100 countries, including Indonesia, New Zealand, and the U.S. (Inglehart et al., 2014).

Political elaboration. Political elaboration referred to the extent to which people elaborate on political discussions and conversations they have been engaged in (Eveland, 2004), and was assessed with a four-item scale which included statements, such as "I often find myself thinking 
about my conversations with other people about politics and public affairs after the discussion has ended," ( 1 = disagree completely to 7 = agree completely). This scale showed very good internal consistency across the sample groups (Indonesia =0.925; New Zealand =0.908; the U.S. =0.914).

Internal political efficacy. Internal political efficacy was defined as beliefs about one's own competence to understand, and to participate effectively in politics, was measured with a fouritem Internal Political Efficacy Scale drawn from the National Election Survey (Niemi, Craig, \& Mattei, 1991). The scale included items, such as "I consider myself well qualified to participate in politics" ( 1 = disagree completely to 7 = agree completely $)$. This scale provided good internal consistency for New Zealand (0.760) and the U.S. (0.761) but was less than acceptable for Indonesia (0.400).

For the Indonesian sample group, all criterion measures were translated into Bahasa Indonesia using the committee method (Brislin, 1980).

\section{Results}

To test the replicability of the PSR-P factor structure across countries (Hypothesis 3), we first performed a confirmatory factor analysis with MLR estimator (50,000 iterations) for individual sample groups (Muthén \& Muthén, 2006). As expected, the single latent factor model of the PSR-P consistently produced very good model fit for Indonesia $\left(\chi^{2}(2)=2.241, p=.326\right.$; RMSEA $=0.024, \mathrm{CFI}=0.998, \mathrm{TLI}=0.995, \mathrm{SRMR}=0.015)$, New Zealand $\left(\chi^{2}(2)=6.215, p=\right.$ 0.045; RMSEA $=0.076, \mathrm{CFI}=0.988, \mathrm{TLI}=0.963, \mathrm{SRMR}=0.017)$, and the U.S. $\left(\chi^{2}(2)=4.321\right.$, $p=0.115 ; \mathrm{RMSEA}=0.060, \mathrm{CFI}=0.992, \mathrm{TLI}=0.976, \mathrm{SRMR}=0.016)$. Next, we performed invariance measurement tests to assess whether the factor structure of the PSR-P scale and the 
meaning of the items were equal across sample groups. Measurement invariance was examined using the Satorra-Bentler chi-square $\left(S B-\chi^{2}\right)$ difference test with scaling correction (Satorra \& Bentler, 2011). Our analysis revealed that the configural model $\left[\chi^{2}(6)=11.525, p=0.073\right.$; RMSEA $=0.055, \mathrm{CFI}=0.992, \mathrm{TLI}=0.977, \mathrm{SRMR}=0.016]$, metric model $\left[\chi^{2}(12)=18.399, p=0.104 ;\right.$ $\mathrm{RMSEA}=0.042, \mathrm{CFI}=0.991, \mathrm{TLI}=0.987, \mathrm{SRMR}=0.058]$, and scalar model of the PSR-P scale $\left[\chi^{2}(18)=33.833, p=0.013 ; \mathrm{RMSEA}=0.054, \mathrm{CFI}=0.978, \mathrm{TLI}=0.978, \mathrm{SRMR}=0.076\right]$ produced good model fits. More importantly, the model yielded full metric $\left[S B-\chi^{2}(\Delta d f=6)=5.954, p=\right.$ $0.428]$ and scalar invariance $\left[S B-\chi^{2}(\Delta d f=6)=16.548, p=0.011\right]$ across sample groups. In summary, these results supported Hypothesis 3 in that the factor structure of PSR-P was replicable, and the meaning ascribed to the items were invariant across selected sample groups.

\section{Insert Table 4 here}

Given measurement invariance for the PSR-P scale, we further tested the mean difference of parasocial relationships with politicians across countries. As shown in Figure 1, we found a significant mean difference of the PSR-P scale between sample groups, $F(2)=45.79, p<$ $0.001, f=0.346$. More specifically, the mean score of the Indonesian sample was significantly higher than both the US $(\Delta \bar{x}=0.240, S E=0.102,95 \%$ CI $[0.041 \quad 0.44], f=0.086)$ and New Zealand samples $(\Delta \bar{x}=0.856, S E=0.993,95 \%$ CI $[0.6701 .06], f=0.375)$. On the other hand, the US participants showed a significantly higher score on political parasocial relationships than their New Zealand counterparts, $\Delta \bar{x}=0.625, S E=0.087,95 \%$ CI $[0.454 \quad 0.795], f=0.260$. Supporting Hypothesis 4 , these results demonstrate that the type of political system and the democratic maturity of a country are important contextual factors for parasocial relationships with politicians. 


\section{Insert Figure 1 here}

In terms of discriminant validity, we found non-significant correlations between PSRP and RWA for both New Zealand $(r=-0.021, p>0.05)$ and the U.S. sample groups $(r=-0.098$, $p>0.05)$. This correlation, however, was small for the Indonesian samples $(r=0.148, p<0.05)$ based on Cohen's criteria (1998). In addition, we found non-significant correlations of PSR-P and Benevolent Authority for the Indonesian $(r=0.039, p>0.05)$ and the U.S. $(r=0.073, p>0.05)$ sample groups, and a small yet significant correlation for the New Zealand sample $(r=0.153, p<$ 0.01). These findings confirmed that PSR-P was distinct from various forms of authoritarianism. Moreover, the relationships between PSR-P and Political Ideology were mixed yet consistently weak across sample groups. The correlation was weak and positive for the Indonesians $(r=0.148$, $p<0.05)$, non-significant for the New Zealanders $(r=-0.02, p>0.05)$, weak and negative for the U.S. participants $(r=-0.138, p<0.05)$. In summary, based on these inconsistent and weak correlations between parasocial relationship and authoritarianism, benevolent authority, and political ideology across sample groups, we concluded that the PSR-P scale had discriminant validity with these concepts, supporting Hypothesis 5 (see Table 4).

As for predictive validity, we found significant and consistent correlations between PSR-P and two of the criterion variables across countries: political elaboration (Indonesia, $r=$ 0.257, $p<0.01$; New Zealand, $r=0.221, p<0.01$; the U.S., $r=0.194, p<0.01$ ), and political interest (Indonesia, $r=0.334, p<0.01$; New Zealand, $r=0.345, p<0.01$; the U.S., $r=0.382, p<$ 0.01). Meanwhile, significant and positive correlations between PSR-P and internal political efficacy were found for New Zealand $(r=0.220, p<0.01)$ and the US $(r=0.262, p<0.01)$, but 
not for Indonesia $(r=0.242, p<0.01)$. Again, these results supported Hypothesis 6 in that PSR-P was able to produce adequate predictive validity across sample groups.

\section{General discussion}

Our aim in this study was to develop a scale to measure ordinary people's feeling of distant intimacy (or, parasocial relationship) with political figures. We found that the four items of PSR-P scale developed had sufficient psychometric properties to measure a parasocial relationship with a political figure as an individual difference. PSR-P exhibited convergent validity $(r=.60)$ compared with the PPSR scale which was designed to measure parasocial relationships with political figures (but does not distinguish this from parasocial interaction). Moreover, PSR-P also demonstrated convergent validity by producing a more moderate correlation with the PSI-Process scale $(r=.45)$ that was designed to measure parasocial interaction. In contrast, the PPSR scale showed a high correlation with PSI-Process and produced insufficient model fit, implying that there might be some difficulties related to the construct validity of the scale. Lastly, the PSR-P scale also provided evidence of factor replicability, discriminant validity, and predictive validity based on samples from socio-politically diverse countries, such as Indonesia, New Zealand, and the US.

The construct of parasocial relationship as measured by the PSR-P implies that interpersonal processes are involved in the relationship between voters and candidates. Instead of relying solely on the candidates' ideology and authority, some individuals utilised an interpersonal framework in the understanding and formation of their political orientation towards their preferred political figure. As shown in the current study, such interpersonal-based political dispositions exhibited weak and inconsistent correlations with political ideology, right-wing authoritarianism, 
and benevolent authority across socio-political contexts. Parasocial theory suggests that individuals who form parasocial relationships with a distant figure like a political candidate are more likely to see the figure as though she or he was a higher status acquaintance - in other words, as an asymmetrical relationship (R. B. Rubin \& Mchugh, 1987). For these individuals approximately $64 \%$ of nationally representative samples from three countries - the nominated political figure is theorised to serve as a source of comfort, enjoyment, and a role model (Giles, 2002) to simplify their understanding of national politics. The PSR-P scale allows researchers to empirically investigate further such propositions across countries with a psychometrically robust measure of political parasocial relationship.

Another important finding related to the linkage between two key concepts in parasocial theory, parasocial interaction and parasocial relationship. Horton and Wohl (1956) initially asserted that one's parasocial relationship with a distant figure develops as she or he frequently encounters the given figure through mass media over time. Elaborating the theory further, Hartmann and colleagues (Dibble et al., 2016; Hartmann \& Goldhoorn, 2011; Klimmt et al., 2006; Schramm \& Hartmann, 2008) pointed out that the feeling of distant intimacy with a particular figure (i.e., parasocial relationship) may evolve from one's repeated experience of conversational take and give with the given figure through media - that is, parasocial interaction - even though this might not be the only path. Our findings supported such notions by showing a positive, moderate, and significant correlation between parasocial interactions (as measured with the PSIProcess scale) and parasocial relationships with political figures (as measured with the PSR-P scale). 
Furthermore, central to parasocial theory is the idea that some people are motivated to nurture parasocial relationships, just like real interpersonal relationships. The theory posits that individuals who are in a parasocial relationship with a particular figure are more likely to find out more about the given figure's private and social life (Horton \& Wohl, 1956), and learn vicariously from the figure's experiences (Dunn \& Nisbett, 2014). Indicative of such tendencies, our analysis revealed that parasocial relationships with political figures had consistently significant and positive associations with a higher interest in politics, greater elaboration of political information, and higher internal political efficacy across sample groups. These results were consistent with previous findings from Dunn and Nisbett's (2004) study, and also showed that such patterns could be found across socio-political settings.

It is important to note that the type of political system and the maturity of democracy in a country appear to have a pivotal contextual role for forming parasocial relationships with politicians. We found that the intensity of parasocial attachments with politicians was significantly higher in presidential systems (Indonesia and the US) than in a parliamentary system (New Zealand). Additionally, the democratically emerging presidential system of Indonesia was found to show significantly higher intensity of political parasocial relationships than the more established presidential system of the USA. These findings imply that both the type of political system and its democratic maturity should be taken into account as a critical macro-level factor in future research on parasocial relationships with politicians in cross-national contexts.

Despite the findings, there are limitations to the present study. First, the exploratory and confirmatory analyses in Study 2 were conducted based on a convenience adult sample. While the sample size was arguably sufficient to perform both EFA and CFA as indicated by the 
sample adequacy tests, the use of convenience samples might limit the generalisability of the scale assessment. This issue, however, was well addressed in Study 3, with the replications of the PSR-P measurement model using more representative and cross-cultural sample groups. Second, the use of an open-ended question as the opening part of the scale (i.e., please indicate, who is your most favoured political figure at the national stage?) reduced the sample size in Study 3. The fact that some individuals were not able to bring any specific figures in their mind when completing the scale suggests that not all individuals (35.9\% in this study) are equally prone to form parasocial relationships with political figures. Nonetheless, we considered this approach appropriate for the initial assessment of the scale in order to reduce measurement errors as suggested by R. B. Rubin and McHugh (1987). However, we suggest that future studies may set specific political figures (e.g., presidential candidates, prominent Congress members, and so forth) as the target of parasocial relationship evaluation to further expand the generalizeability of the PSR-P.

In conclusion, the PSR-P scale provided robust psychometric properties to measure parasocial relationships with politicians. Theoretically, the scale can be utilised to advance the application of parasocial theory as an explanatory framework of political behaviours across countries. In terms of the practical utility, the PSR-P scale may be useful in public opinion or electoral surveys to assess the intensity of the voters' parasocial attachments cultivated by particular candidates. We believe that parasocial theory offers important insights into the field of political psychology and is particularly relevant amid the trends in many democratic countries where the electoral politics are increasingly centred around political figures and their usage of social media platforms. 


\section{References}

Adorno, T. W., Frenkel-Brunswik, E., Levinson, D. J., \& Sanford, R. N. (1950). The authoritarian personality. New York, NY, USA: Harper.

Brislin R.W. (1980) Cross-Cultural Research Methods. In: Altman I., Rapoport A., Wohlwill J.F. (eds) Environment and Culture. Human Behavior and Environment (Advances in Theory and Research), vol 4. Springer, Boston, MA.

Brown, T. A. (2014). Confirmatory factor analysis for applied research. New York, NY: Guilford Publications.

Campbell, D. T., \& Fiske, D. W. (1959). Convergent and discriminant validation by the multitraitmultimethod matrix. Psychological Bulletin, 56(2), 81.

Caprara, G. V., \& Zimbardo, P. G. (2004). Personalizing politics: a congruency model of political preference. American Psychologist, 59(7), 581. doi: 10.1037/0003-066X.59.7.581

Cohen, E. L., \& Hoffner, C. (2016). Finding meaning in a celebrity's death: The relationship between parasocial attachment, grief, and sharing educational health information related to Robin Williams on social network sites. Computers in Human Behavior, 65, 643-650.

Cohen, J. (1988). Statistical power analysis for the behavioral sciences (2nd ed.). Hillsdale, NJ: Erlbaum.

Cohen, J., \& Holbert, R. L. (2018). Assessing the predictive value of parasocial relationship intensity in a political context. Communication Research, 1-26. doi: .org/10.1177/0093650218759446

Cronbach, L.J.; Meehl, P.E. (1955). "Construct validity in psychological tests". Psychological Bulletin. 52 (4): 281-302. doi:10.1037/h0040957.

Dibble, J. L., Hartmann, T., \& Rosaen, S. F. (2016). Parasocial interaction and parasocial relationship: Conceptual clarification and a critical assessment of measures. Human Communication Research, 42(1), 21-44.

Duckitt, J. (2001). A dual-process cognitive-motivational theory of ideology and prejudice. Advances in Experimental Social Psychology, 33, pp. 41-113.

Dunn, S. G. S., \& Nisbett, G. S. (2014). Parasocial interactions online: Candidate intimacy in webpages and Facebook. The Journal of Social Media in Society, 3(2).

Eveland, J., William P. (2004). The effect of political discussion in producing informed citizens: The roles of information, motivation, and elaboration. Political Communication, 21(2), 177-193.

Eyal, K., \& Cohen, J. (2006). When good friends say goodbye: A parasocial breakup study. Journal of Broadcasting \& Electronic Media, 50(3), 502-523.

Gabriel, S., Paravati, E., Green, M. C., \& Flomsbee, J. (2018). From Apprentice to President: The Role of Parasocial Connection in the Election of Donald Trump. Social Psychological and Personality Science, 1-9. doi: 10.1177/1948550617722835

Garzia, D. (2011). The personalization of politics in Western democracies: Causes and consequences on leader-follower relationships. The Leadership Quarterly, 22(4), 697-709. doi:10.1080/23808985.2010.11679101

Garzia, D. (2013). Changing parties, changing partisans: The personalization of partisan attachments in Western Europe. Political Psychology, 34(1), 67-89.

Giles, D. C. (2002). Parasocial interaction: A review of the literature and a model for future research. Media Psychology, 4(3), 279-305. 
Gleason, T. R., Theran, S. A., \& Newberg, E. M. (2017). Parasocial interactions and relationships in early adolescence. Frontiers in Psychology, 8, 255.

Romero, E., Villar, P., Gómez-Fraguela, J. A., \& López-Romero, L. (2012). Measuring personality traits with ultra-short scales: A study of the Ten Item Personality Inventory (TIPI) in a Spanish sample. Personality and Individual Differences, 53(3), 289-293.

Hair, J. F., Black, W. C., Babin, B. J., Anderson, R. E., \& Tatham, R. L. (2006). Multivariate data analysis (Vol. 6): Upper Saddle River, NJ: Pearson Prentice Hall.

Hartmann, T., \& Goldhoorn, C. (2011). Horton and Wohl revisited: Exploring viewers' experience of parasocial interaction. Journal of Communication, 61(6), 1104-1121

Hinkin, T. R. (1998). A brief tutorial on the development of measures for use in survey questionnaires. Organizational research methods, 1(1), 104-121.

Horton, D., \& Strauss, A. (1957). Interaction in audience-participation shows. American Journal of Sociology, 62(6), 579-587.

Horton, D., \& Wohl, R. R. (1956). Mass-Communication and Para-Social Interaction Observations on Intimacy at a Distance. Psychiatry, 19(3), 215-229.

Hu, L. T., \& Bentler, P. M. (1999). Cutoff criteria for fit indexes in covariance structure analysis: Conventional criteria versus new alternatives. Structural Equation Modeling, 6(1), 1-55. doi:10.1080/10705519909540118.

Kaiser, H. F., \& Rice, J. (1974). Little jiffy, mark IV. Educational and Psychological Measurement, 34(1), 111-117.

Karvonen, L. (2007). The personalization of politics. What does research tell us so far, and what further research is in order. Paper presented at the 4th ECPR Conference, Pisa.

Kerlinger, F. N. (1986). Fundamentals of behavioral research. New York: Holt, Rinehart, and Winston.

Klimmt, C., Hartmann, T., \& Schramm, H. (2006). Parasocial interactions and relationships. Psychology of Entertainment, 291-313.

Lawshe, C. H. (1975). A quantitative approach to content validity 1. Personnel Psychology, 28(4), 563-575.

Lenz, G. S. (2013). Follow the leader?: how voters respond to politicians' policies and performance. Chicago, IL: University of Chicago Press.

Liu, J. H. f., Yeh, K. H., Wu, C. W., Liu, L., \& Yang, Y. (2015). The importance of gender and affect in the socialization of adolescents' beliefs about benevolent authority: Evidence from Chinese indigenous psychology. Asian Journal of Social Psychology, 18(2), 101-114.

Lobo, M. C., \& Curtice, J. (2014). Personality Politics?: The Role of Leader Evaluations in Democratic Elections. Oxford, UK: OUP Oxford.

McCutcheon, L. E., Lange, R., \& Houran, J. (2002). Conceptualization and measurement of celebrity worship. British Journal of Psychology, 93(1), 67-87.

Mietzner, M. (2015). Reinventing Asian Populism: Jokowi's Rise, Democracy, and Political Contestation in Indonesia. Policy Studies(72), 0_1

Milojev, P., Osborne, D., Greaves, L. M., Barlow, F. K., \& Sibley, C. G. (2013). The Mini-IPIP6: Tiny yet highly stable markers of Big Six personality. Journal of Research in Personality, 47(6), 936-944.

Muthén, L. K., \& Muthén, B. O. (2006). Mplus Version 7 user's guide. Los Angeles, CA: Muthén \& Muthén.

Niemi, R. G., Craig, S. C., \& Mattei, F. (1991). Measuring internal political efficacy in the 1988 National Election Study. American Political Science Review, 85(4), 1407-1413. 
Romero, E., Villar, P., Gómez-Fraguela, J. A., \& López-Romero, L. (2012). Measuring personality traits with ultra-short scales: A study of the Ten Item Personality Inventory (TIPI) in a Spanish sample. Personality and Individual Differences, 53(3), 289-293.

Rubin, A. M., \& Perse, E. M. (1987). Audience activity and television news gratifications. Communication Research, 14(1), 58-84.

Rubin, A. M., Perse, E. M., \& Powell, R. A. (1985). Loneliness, parasocial interaction, and local television news viewing. Human Communication Research, 12(2), 155-180.

Rubin, R. B., \& Mchugh, M. P. (1987). Development of Parasocial Interaction Relationships.

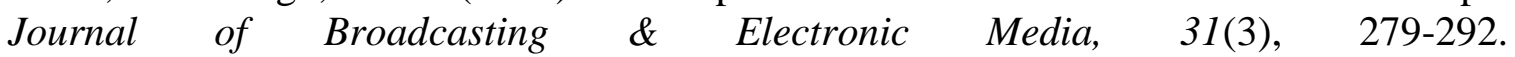
doi:10.1080/08838158709386664

Satorra, A., \& Bentler, P. (2011). Scaling corrections for statistics in covariance structure analysis. Department of Statistics, UCLA.

Schneider, W. (1994). The New Populism. Political Psychology, 15(4), 779-784. doi: $10.2307 / 3791636$

Schramm, H., \& Hartmann, T. (2008). The PSI-Process Scales. A new measure to assess the intensity and breadth of parasocial processes. Communications, 33(4), 385-401.

Schramm, H., \& Wirth, W. (2010). Testing a universal tool for measuring parasocial interactions across different situations and media. Journal of Media Psychology, 22(1), pp. 6-36.

Slater, M. D., Ewoldsen, D. R., \& Woods, K. W. (2018). Extending conceptualization and measurement of narrative engagement after-the-fact: Parasocial relationship and retrospective imaginative involvement. Media Psychology, 21(3), 329-351

Stever, G. S. (2017). Parasocial Theory: Concepts and Measures. The International Encyclopedia of Media Effects, 1-12.

The Economist Intelligence Unit (2018). Democracy Index. Retrieved from: https://infographics.economist.com/2018/DemocracyIndex/

Tukachinsky, R. H. (2011). Para-romantic love and para-friendships: Development and assessment of a multiple-parasocial relationships scale. American Journal of Media Psychology, 3(1/2), 73-94.

Weisberg, H. F., \& Rusk, J. G. (1970). Dimensions of candidate evaluation. American Political Science Review, 64(04), 1167-1185. 
Figure 1. The mean score differences of the PSR-P scale across sample groups

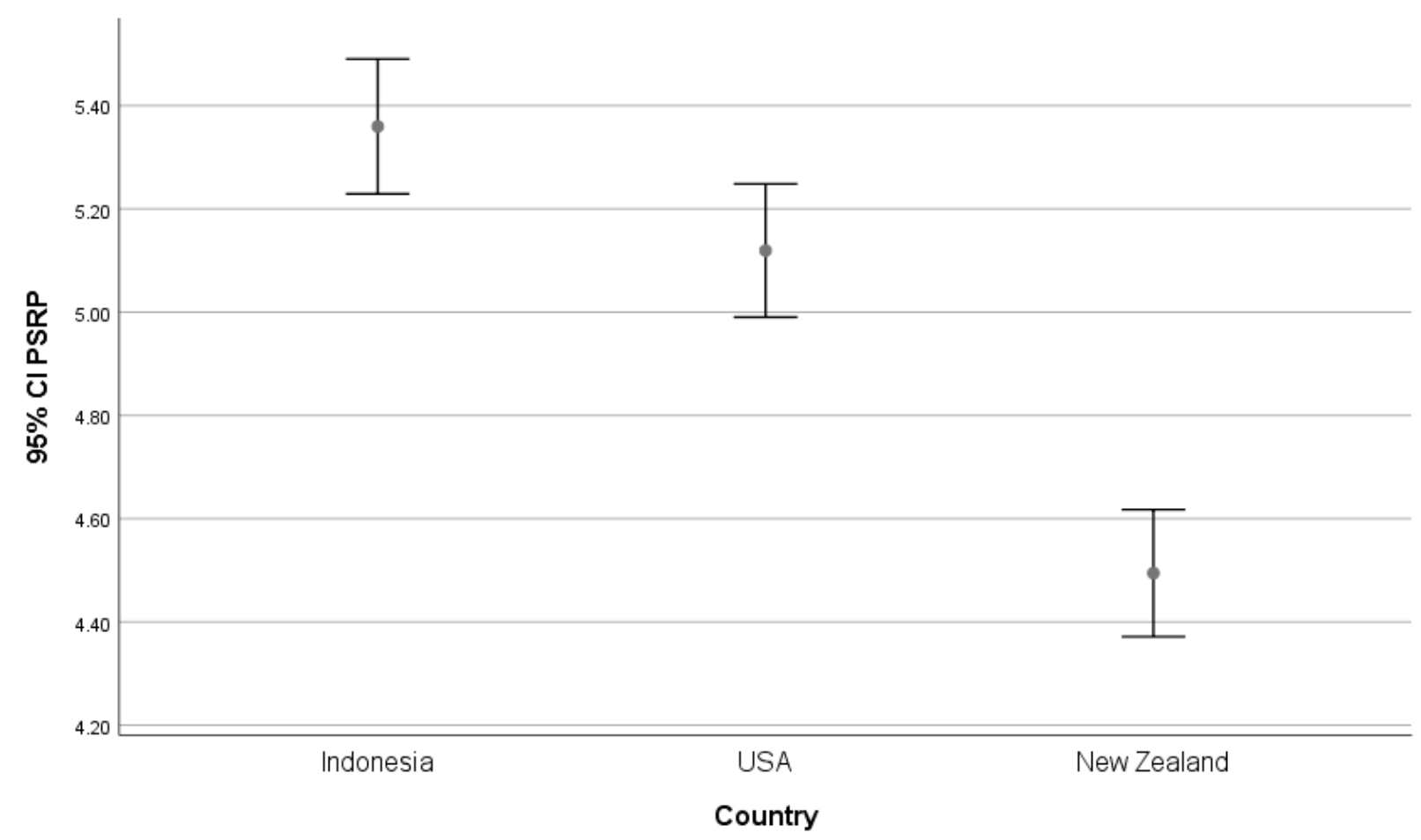


PARASOCIAL RELATIONSHIPS WITH POLITICIANS

Table 1. The CVR values of the preliminary PSR-P items

\begin{tabular}{llccc}
\hline No. & \multicolumn{1}{c}{ Item list } & N & Ne & CVR \\
\hline 1 & I am very sympathetic to what he or she wants to achieve. & 20 & 19 & .9 \\
2 & I find his or her life story to be inspiring. & 20 & 15 & .5 \\
3 & I would love to have dinner with him or her. & 20 & 15 & .5 \\
4 & 20 & 20 & 1 \\
5 & I am moved by his or her speeches. & 20 & 20 & 1 \\
& The criticism that is directed at him or her makes me feel & & \\
angry. & 20 & 17 & .7 \\
$\quad$ I don't care about how much political party support he or she & & & \\
& has. & 20 & 5 & $-.5^{*}$ \\
\hline
\end{tabular}

Note: *discarded 
Table 2. Factor loadings of the preliminary and final items of the PSR-P scale

\begin{tabular}{|c|c|c|c|c|}
\hline \multirow{2}{*}{ No. } & \multirow{2}{*}{ Items } & \multicolumn{2}{|c|}{ Step 1: EFA } & \multirow{2}{*}{$\begin{array}{l}\text { Step 2: } \\
\text { CFA }\end{array}$} \\
\hline & & Factor 1 & Factor 2 & \\
\hline 1 & $\begin{array}{l}\text { I am very sympathetic to what he or she wants to } \\
\text { achieve. }\end{array}$ & 0.684 & 0.213 & 0.717 \\
\hline 2 & I find his or her life story to be inspiring. & 0.649 & - & 0.636 \\
\hline 3 & I would love to have dinner with him or her. & 0.489 & - & 0.487 \\
\hline 4 & I am moved by his or her speeches. & 0.615 & 0.161 & 0.634 \\
\hline 5 & $\begin{array}{l}\text { The criticism that is directed at him or her makes } \\
\text { me feel angry. }\end{array}$ & - & $0.364 *$ & - \\
\hline \multirow[t]{2}{*}{6} & $\begin{array}{l}\text { I don't care about how much political party support } \\
\text { he or she has. }\end{array}$ & - & $0.629 *$ & - \\
\hline & Initial eigenvalues & 38 & 19 & 54 \\
\hline
\end{tabular}

Note: *discarded 
Table 3. Descriptive statistics, Cronbach's alpha, model fit indices and Pearson's correlation coefficients of the PSR-P, PPSR, and PSI-Process

\begin{tabular}{|c|c|c|c|c|c|c|c|c|c|c|c|c|}
\hline \multirow[b]{2}{*}{ Measures } & \multirow[b]{2}{*}{ Mean } & \multirow[b]{2}{*}{ SD } & \multirow[b]{2}{*}{$A$} & \multicolumn{7}{|c|}{ Model fit indices } & \multicolumn{2}{|c|}{ Pearson's $r$} \\
\hline & & & & $\chi^{2}$ & $d f$ & $p$ & RMSEA & CFI & TLI & SRMR & PPSR & $\begin{array}{l}\text { PSI- } \\
\text { Process }\end{array}$ \\
\hline PSR-P & 5.88 & .765 & .707 & 1.286 & 2 & .526 & .000 & 1.00 & 1.022 & .013 & $.600^{* *}$ & $.451^{* *}$ \\
\hline PPSR & 5.10 & .901 & .894 & $20.39^{\dagger}$ & 2 & .000 & .208 & .952 & .856 & .032 & - & $.798^{* *}$ \\
\hline $\begin{array}{l}\text { PSI- } \\
\text { Process }\end{array}$ & 4.24 & .881 & .849 & $1.087^{\dagger}$ & 2 & .581 & .000 & 1.00 & 1.012 & .014 & - & 1.00 \\
\hline
\end{tabular}

Note: "based on parcelled items; ${ }^{*} p<.05 ; * * p<.001$ 
Table 4. Descriptive statistics, Cronbach's alpha, and the correlation coefficients of the PSR-P and discriminant and predictive validity criterion variables

\begin{tabular}{|c|c|c|c|c|c|c|c|c|c|c|c|c|}
\hline \multirow[b]{2}{*}{ Variables } & \multicolumn{4}{|c|}{ Indonesia } & \multicolumn{4}{|c|}{ New Zealand } & \multicolumn{4}{|c|}{ US } \\
\hline & Mean & $S D$ & $\alpha$ & $R$ & Mean & $S D$ & $a$ & $r$ & Mean & $S D$ & $\alpha$ & $r$ \\
\hline PSR-P & 5.36 & 0.95 & .879 & 1 & 4.49 & 1.20 & .846 & 1 & 5.12 & 1.18 & .847 & 1 \\
\hline \multicolumn{13}{|l|}{ Discriminant validity: } \\
\hline $\begin{array}{l}\text { (1). Right-wing } \\
\text { authoritarianism }\end{array}$ & 5.37 & 0.78 & .414 & $.146^{*}$ & 4.51 & 1.23 & .728 & -0.021 & 4.42 & 1.35 & .766 & -0.098 \\
\hline (2). Benevolent authority & 3.50 & 1.28 & .780 & 0.039 & 3.92 & 1.33 & .849 & $.153^{* *}$ & 3.03 & 1.21 & .794 & 0.073 \\
\hline (3). Political Ideology & 6.44 & 2.17 & .917 & $.148^{*}$ & 5.11 & 2.13 & .938 & -0.02 & 5.54 & 3.01 & .959 & $-.138^{*}$ \\
\hline \multicolumn{13}{|l|}{ Predictive validity: } \\
\hline (4). Political elaboration & 4.06 & 1.33 & .925 & $.257^{* *}$ & 3.81 & 1.49 & .908 & $.221^{* *}$ & 3.85 & 1.58 & .914 & $.194^{* *}$ \\
\hline (5). Political interest & 4.5 & 1.4 & n. $a$. & $.329^{* *}$ & 4.60 & 1.51 & n. $a$. & $.353^{* *}$ & 5.19 & 1.52 & n. $a$. & $.364^{* *}$ \\
\hline (6). Political efficacy & 4.02 & 0.98 & .400 & .020 & 4.10 & 1.25 & .760 & $.221^{* *}$ & 4.26 & 1.34 & .761 & $.248^{* * *}$ \\
\hline
\end{tabular}

Note: $* \mathrm{p}<.05, * * p<.01$ 
Appendix: List of the most favored political figures from Study 2 and Study 3

\begin{tabular}{|c|c|c|c|c|c|c|c|}
\hline \multirow{2}{*}{\multicolumn{2}{|c|}{$\begin{array}{c}\text { Study } 2 \\
\text { Indonesia }\end{array}$}} & \multicolumn{6}{|c|}{ Study 3} \\
\hline & & Indonesia & & New Zealar & & US & \\
\hline Political figures & Freq & Political figures & Freq & Political figures & Freq & Political figures & Freq \\
\hline Joko Widodo & 65 & $\begin{array}{l}\text { Basuki Tjahaja } \\
\text { Purnama }\end{array}$ & 55 & John Key & 140 & Donald Trump & 60 \\
\hline $\begin{array}{l}\text { Basuki Tjahaja } \\
\text { Purnama }\end{array}$ & 28 & Joko Widodo & 46 & Winston Peters & 98 & Bernie Sanders & 55 \\
\hline Ridwan Kamil & 21 & Ridwan Kamil & 18 & Andrew Little & 21 & Hilary Clinton & 48 \\
\hline Anies Baswedan & 17 & Prabowo Subianto & 17 & Jacinda Ardern & 17 & Ted Cruz & 33 \\
\hline $\begin{array}{l}\text { Bacharuddin Jusuf } \\
\text { Habibie }\end{array}$ & 13 & Soeharto & 15 & Meteria Turei & 17 & Barack Obama & 32 \\
\hline Mahfud MD & 13 & $\begin{array}{l}\text { Bacharuddin Jusuf } \\
\text { Habibie }\end{array}$ & 11 & Paula Bennet & 11 & John Kasich & 20 \\
\hline Prabowo Subianto & 13 & $\begin{array}{l}\text { Susilo Bambang } \\
\text { Yudhoyono }\end{array}$ & 7 & Bill English & 7 & Paul Ryan & 14 \\
\hline Susi Pudjiastuti & 5 & Tri Rismaharini & 5 & David Seymore & 6 & $\begin{array}{l}\text { Elizabeth } \\
\text { Warren }\end{array}$ & 13 \\
\hline Amien Rais & 4 & Mahfud MD & 4 & Peter Dunne & 5 & Ben Carson & 9 \\
\hline Sri Mulyani & 4 & Abdurrahman Wahid & 3 & Phil Goff & 5 & Marco Rubio & 8 \\
\hline Anis Matta & 3 & Hidayat Nur Wahid & 3 & Judith Collins & 4 & Bill Clinton & 5 \\
\hline Tri Rismaharini & 3 & Surya Paloh & 3 & Annette King & 3 & Carly Fiorina & 4 \\
\hline Fahri Hamzah & 2 & Ahmad Heriyawan & 2 & $\begin{array}{l}\text { Grant } \\
\text { Robertson }\end{array}$ & 3 & Joe Biden & 3 \\
\hline Ganjar Pranowo & 2 & Amien Rais & 2 & James Shaw & 3 & $\begin{array}{l}\text { Condoleeza } \\
\text { Rice }\end{array}$ & 2 \\
\hline Sandiaga Uno & 2 & Ki Hajar Dewantara & 2 & Amy Adams & 2 & Jeb Bush & 2 \\
\hline $\begin{array}{l}\text { Susilo Bambang } \\
\text { Yudhoyono }\end{array}$ & 2 & $\begin{array}{l}\text { Megawati Sukarno } \\
\text { Putri }\end{array}$ & 2 & David Shearer & 2 & Joe Manchin & 2 \\
\hline $\begin{array}{l}\text { Agus Harimurti } \\
\text { Yudhoyono }\end{array}$ & 1 & Moh Hatta & 2 & Jan Logie & 2 & John McCain & 2 \\
\hline Airlangga Hartarto & 1 & Soekarno & 2 & Kelvin Davis & 2 & Amy Klobuchar & 1 \\
\hline Akbar Faisal & 1 & Susi Pujiastuti & 2 & Nathan Guy & 2 & Chris Christie & 1 \\
\hline Dinopatti Djalal & 1 & Ganjar Pranowo & 1 & Maggie Barry & 2 & Collin Peterson & 1 \\
\hline $\begin{array}{l}\text { Eko Sriyanto } \\
\text { Galgendu }\end{array}$ & 1 & Retno Marsudi & 1 & Steven Joyce & 2 & Corey Booker & 1 \\
\hline Emil Dardak & 1 & Ruhut Sitompul & 1 & Stuart Nash & 2 & Gary Johnson & 1 \\
\hline Hatta Rajasa & 1 & Sandiaga Uno & 1 & Bob Parker & 2 & J.F. Kennedy & 1 \\
\hline Jusuf Kalla & 1 & $\begin{array}{l}\text { Sri Sultan } \\
\text { Hamengkubuwono IX }\end{array}$ & 1 & Colin Craig & 1 & Jeff Flake & 1 \\
\hline $\begin{array}{l}\text { Khofifah Indar } \\
\text { Parawansa }\end{array}$ & 1 & & & David Clark & 1 & Kamala Harris & 1 \\
\hline Retno Marsudi & 1 & & & Helen Clarke & 1 & $\begin{array}{l}\text { Michael } \\
\text { Bloomberg }\end{array}$ & 1 \\
\hline Rizal Ramli & 1 & & & Hone Harawera & 1 & Mike Amyx & 1 \\
\hline Rocky Gerung & 1 & & & $\begin{array}{l}\text { lain Lees- } \\
\text { Galloway }\end{array}$ & 1 & Mike Coffman & 1 \\
\hline Salim Segaf Al-Jufri & 1 & & & Julian Crawford & 1 & Steve Scalise & 1 \\
\hline Soekarno & 1 & & & Megan Woods & 1 & Tulsi Gabbard & 1 \\
\hline Tuan Guru Bajang & 1 & & & & & & \\
\hline
\end{tabular}

